REVISTA DE GEOCIÊNCIAS DO NORDESTE

Northeast Geosciences Journal

v. $7, \mathrm{n}^{\circ} 2(2021)$

ISSN: 2447-3359

https://doi.org/10.21680/2447-3359.2021v7n2ID19495

\title{
PONTENCIALIDADES TURÍSTICAS DA PRAIA DE PONTA VERDE, SÃO JOSÉ DE RIBAMAR-MA
}

\begin{abstract}
Marcelino Silva Farias Filho ${ }^{1}$; Teresa Cristina
Cantanhede Borges ${ }^{2}$; Sergio da Silva de Araujo ${ }^{3}$; Jacenilde Cristina Braga Borges ${ }^{4}$
\end{abstract}

${ }^{1}$ Doutor em Agronomia, Docente da Universidade Federal do Maranhão - UFMA, São Luís/MA

ORCID: https://orcid.org/0000-0001-6153-5293

E-mail: marcelino.farias@ufma.br

${ }^{2}$ Mestre em saúde e Ambiente, da UFMA de São Luís/ MA do Brasil.

ORCID: https://orcid.org/0000-0001-6879-6242

Email: teresacantanhede09@gmail.com

${ }^{3}$ Mestrando pelo Programa de Pós Graduação em Geografia da Universidade Federal do Maranhão-UFMA, São Luís-MA, Brasil..

ORCID: https://orcid.org/0000-0003-0904-3819

Email: silvaraujo4@gmail.com

${ }^{4}$ Mestre em saúde e Ambiente, da UFMA de São Luís/ MA do Brasil.

ORCID: https://orcid.org/0000-0001-7094-3299

Email: jacenil@hotmail.com

\section{Resumo}

O turismo é uma das atividades econômicas que mais crescem no mundo, e no Brasil vem ganhando notoriedade principalmente por seus elementos atrativos paisagísticos, naturais e culturais que potencializam a vinda de pessoas de várias partes do mundo para conhecerem estas belezas. Dentre os polos turístico, destaca-se a região Nordeste, onde está situado á área deste estudo, tem seu potencial turístico localizado principalmente em áreas litorâneas, o Maranhão possuí uma extensa área costeira com presença de praias, mangues, dunas, rias e dentre outros elementos de ambientes costeiros, entretanto a exploração desses espaços ocorre de forma desordenada e pouco estruturada, a exemplo de algumas praias no litoral maranhense, como a praia de Ponta Verde localizada no município de São José de Ribamar. A praia apresenta potencialidades pouco conhecidas pelos agentes públicos. Nesse contexto o estudo tomou como base a pesquisa investigativa e a metodologia, que consistiu-se em quatro etapas: levantamento bibliográfico; realização do trabalho de campo; sistematização e análise das informações e coleta de dados, objetivando assim, analisar as potencialidades turisticas da área de estudo, assim como caracterizar e discutir as problemáticas socioambientais. Constatou-se que a praia possui extensa faixa de areia, com potenciais turísticos como falésias e áreas de banho, local de pesca artesanal em camboas, e na proximidade uma área de sítio arqueológico.

Palavras-chave: Dinâmica socioespacial; Falésias; Áreas de encostas.

\section{TOURIST POTENTIALITY OF THE PONTA VERDE BEACH, SÃO JOSÉ DE RIBAMAR-MA}

\section{Abstract}

Tourism is one of the fastest growing economic activities in the world, and in Brazil it is gaining notoriety mainly for the attractive landscapes, natural and cultural elements that appeal to people from various parts of the world to know such beauties. Among the tourist hubs, the Northeast region stands out, which is the study area. Having its tourist potential located mainly in coastal areas, Maranhão has an extensive one, with the presence of beaches, mangroves, dunes, rivers and other elements of coastal environments, however the exploration of these spaces occurs in a disordered and poorly structured way, as in the case of some beaches on the coast of Maranhão, such as the Ponta Verde beach located in the municipality of São José de Ribamar. The beach has a potential little known by public agents. In this context, the study was based on investigative research and methodology, which consisted of four stages: bibliographic survey; fieldwork; systematization and analysis of information and data collection, thus aiming to analyze the tourist potential of the study area, as well as to characterize and discuss socioenvironmental issues. It was found that the beach has an extensive sand strip, with places of tourist potential such as cliffs and bathing areas, a place for artisanal fishing in camboas, and an archaeological site nearby.

Keywords: Socio-spatial dynamics; Cliffs; Hillside areas. 


\section{PENTENCIALES TURísticos DE LA PLAYA PONTA VERDE, SÃO JOSÉ DE RIBAMAR-MA}

\section{Resumen}

El turismo es una de las actividades económicas de más rápido crecimiento en el mundo, y en Brasil viene ganando notoriedad principalmente por sus elementos atractivos paisajísticos, naturales y culturales que potencian la llegada de personas de varias partes del mundo para conoceren estas bellezas. Entre los polos turísticos, se destaca la región Nordeste, dónde está situado el área de este estudio, tiene su potencial turístico ubicado principalmente en zonas litorales, el Maranhão tiene una extensa zona costera con presencia de playas, manglares, dunas, ríos y entre otros elementos de ambientes costeros, sin embargo la exploración de estos espacios ocurre de manera desordenada y poco estructuradas, como ejemplo de algunas playas de la costa de Maranhão, como la playa de Ponta Verde ubicada en el municipio de Sao José de Ribamar. La playa presenta potencialidades poco conocidas por los agentes públicos. En este contexto, el estúdio se basó en una investigación y la metodología que consta de cuatro etapas: búsqueda bibliográfica; realización de trabajo de campo; sistematización de las experiencias y análisis de las informaciones y recogida de datos, objetivando de esta manera, analizar las potencialidades turística del área de estudio, así como caracterizar y discutir las problemáticas socioambientales. Se constató que la playa tiene una larga franja de arena, con potencialidades turísticas como acantilados y espacio de baño, local de pesca artesanal en camboas, y en la proximidad un territorio de sitio arqueológico.

Palabras - clave: Dinámica socioespacial; Acantilados; Áreas de barrancos.

\section{INTRODUÇÃO}

O processo de deslocamento do homem primitivo esteve associado, principalmente, à realização de atividades básicas tais como coleta, caça e a pesca, o que resultou em sua sobrevivência. Nos dias atuais, esse processo de deslocamento tornou-se conhecido como turismo ou fenômeno turístico, geralmente relacionado a viagens, isto é, à visita a um local diferente de sua residência de origem. Seguindo essa linha de pensamento, Ignarra (2003) afirma que quando o homem "passou a viajar, principalmente motivado pela necessidade de comércio com outros povos", desencadeou o processo de deslocamento das pessoas.

De acordo com Ferreira (2007, p. 02), "mais recentemente, a ideia de deslocamento ganhou a denominação de viagem cujos motivos inicialmente baseavam-se na religião, tratamento de saúde, trocas e/ou negócios, cultura e lazer". Nessa primeira fase, a viagem era assistemática, algo espontâneo, em seguida passou a ter um grau de organização ou mesmo programação, de modo que foram criadas agências especializadas para gerenciar este tipo de prática a nível mundial.

No que se refere ao turismo, pode-se dizer que é um fenômeno condicionado a partir de relações e atividades das pessoas que viajam, permanecendo fora de seu local habitual, dentro de um determinado período de tempo - o estipulado em até um ano - por motivos de lazer, negócios e outros afins (CUNHA, 2010).

Segundo Ferreira (2007), o turismo é um elemento que expressa materialmente a lógica capitalista quando estabelece relação com uma dinamicidade do espaço geográfico. Sendo assim, um grande agente transformador deste espaço, dessa maneira, determinado local poderá ser transformado e adaptado, a fim de atender às demandas criadas a partir da vinda de pessoas de outros locais, a saber, turistas, indivíduos que tem sua permanência em dado local por mais de $24 \mathrm{~h}$ ou mesmo o excursionista, este último tem sua permanência contada em menos de $24 \mathrm{~h}$.

Conforme a Organização Mundial do Turismo - OMT (2019), esta atividade (turismo) gera uma movimentação de aproximadamente 1,4 bilhões de turistas/ano no mundo, este dado refere-se ao ano de 2018, desse total o Brasil recebe cerca de 6,6 milhões de turistas/ano. Logo o turismo representa um dos setores que mais contribui para a economia mundial.

$\mathrm{Na}$ perspectiva de trabalhar as potencialidades locais, o Estado do Maranhão em seu territorial abriga uma vasta biodiversidade e geodiversidade, que contribuem para existência de paisagens exuberantes com potencialidades turísticas. De acordo com Costa (2016, p.01) tanto o Brasil quanto Maranhão possuem um turismo "prioritariamente desenvolvido nos espaços litorâneos, que pode transformar o litoral do Maranhão numa fronteira de expansão do turismo litorâneo".

Sendo assim, é de salientar que a área deste estudo encontrase localizada no município de São José de Ribamar, situado no polo turístico de São Luís/MA. Ademais, segundo Bandeira e Dantas (2013, p.124) "esse polo está localizado no extremo norte do estado e abrange a capital, São Luís, a cidade-monumento Alcântara [...] e os municípios de São José de Ribamar, Paço do Lumiar e Raposa, na ilha de São Luís".

Os atrativos turísticos de São José de Ribamar são em maior parte de cunho cultural, somados as belezas paisagisticas naturais como praias, dunas e falésias, os visitantes são atraídos pelas manifestações religiosas presente no local. Segundo Vieira (2011), existem muitas histórias que giram em torno do santo padroeiro, que é São José, uma delas diz que a igreja da cidade teria desabado duas vezes, até ser construída de frente para o mar como era o desejo do Santo. Milhares de fiéis são atraídos todos os anos no mês de setembro para a festa de São José de Ribamar, a concentração das atividades ocorre na praça matriz, onde encontram-se a igreja, as estátuas do santo padroeiro e de outras figuras religiosas.

Bandeira e Dantas (2013) relatam que em São José de Ribamar existe a tranquilidade bucólica e uma bela enseada que garante mistas paisagens a seu ambiente costeiro, com seus atrativos geoturísticos, como praias, mangues e dunas. Entre as praias do município de São José de Ribamar destacam-se: Caúra, Panaquatira, Itapari e Ponta Verde. Esta última, possui uma estrutura natural com elementos paisagísticos exuberantes, representadas por tabuleiros, falésias e faixas de praia que a colocam como um local de potencialidades naturais para o crescimento do turismo, ainda atrelado a tranquilidade.

Dessa forma, este trabalho tem por objetivo, analisar as potencialidades naturais da praia de Ponta Verde em São José de Ribamar/MA para fins turísticos, além de caracterizar e discutir as problemáticas socioambientais deste local. 


\section{METODOLOGIA}

A pesquisa foi delineada por uma abordagem investigativa, partindo de uma série de atividades que envolvem a relação do homem com o ambiente, no qual se considerou as características naturais e sociais, relacionando com as perspectivas de mercado ligadas ao turismo. Dessa forma, foi elaborado um conjunto diferenciado de informações, consistiu-se no ponto de vista dos moradores acerca de possíveis locais com potenciais naturais para o turismo, em primeiro lugar, foi levado em consideração as áreas que estes apontavam como potêncial turístico, em seguida foram feitas visitas ao campo para validação das informações. Desse modo, as informações foram reunidas e acionadas em forma instrumental, sobre linhas sociais e/ou físicas, sob o comando de uma ou mais bases lógicas de investigação (FREITAS, 2017). Essa base lógica seria uma área de praia com existência de elementos naturais paisagísticos que são potenciais turisticos.

A Praia de Ponta Verde está localizada no bairro de Ponta Verde sob as coordenadas de $2^{\circ} 31^{\prime} \mathrm{S}$ e $44^{\circ} 2^{\prime} \mathrm{W}$, conforme mostra a Figura 1:

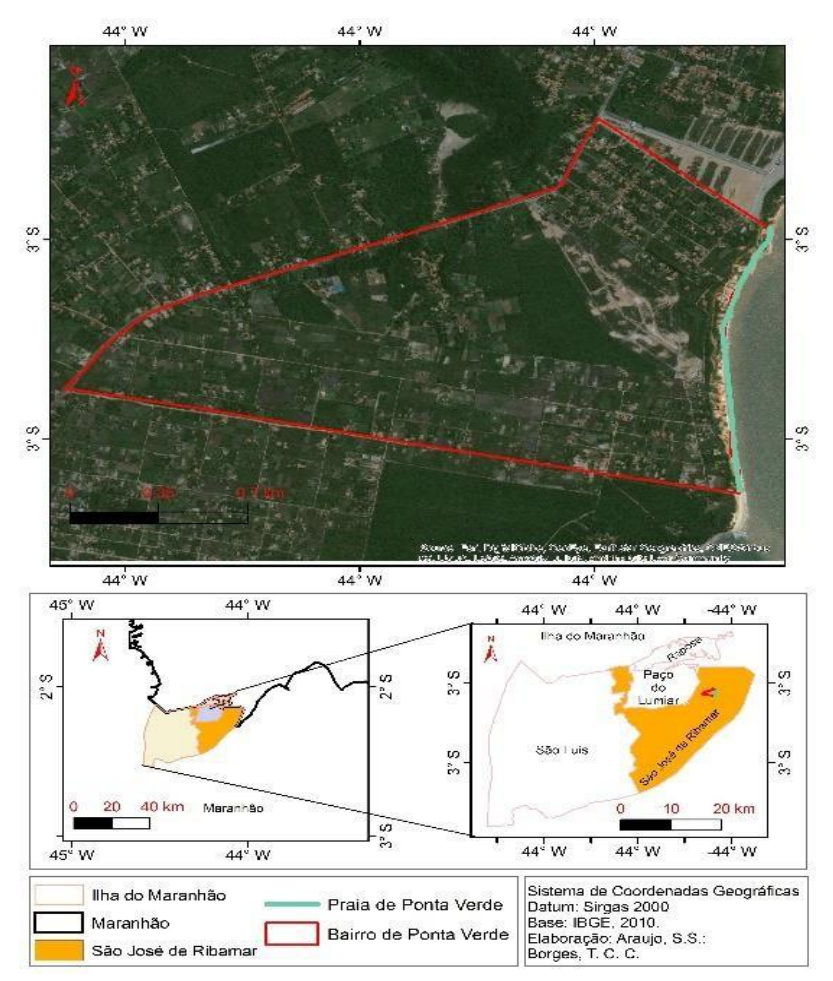

Figura 1 - Localização da praia e do bairro de Ponta Verde, São José de Ribamar-MA. Fonte: Elaboração própria (2019).

As atividades de campo se deram em quatro idas, nos meses de janeiro, fevereiro e março no ano de 2019, para observação e coleta de dados. Nas atividades in loco foram realizados registros fotográficos, atividades de observação do ambiente físico, conversas com banhistas e moradores do entorno da praia.

Os mapas de localização e de atrativos turísticos para fim de delimitação e mensuração da área da praia, foram elaborados e confeccionados a partir das informações e de pontos coletados com o Sistema de Posicionamento Global (GPS). Para a base de dados foi utilizada as malhas territoriais do IBGE (2010) e imagens do Google Earth Pro (2019). Os pontos de atrativos turísticos foram obtidos através do GPS portátil Garmin 10s, os pontos foram marcados in loco e depois georreferenciados no software livre Quantum Gis que também foi utilizado para confecção dos mapas desta pesquisa.

A primeira visita ao campo foi para conhecer e percorrer o trajeto do início ao fim da praia e fazer observação da área de estudo. Na segunda atividade, ocorreu a coleta de pontos com o GPS, e, a fim de conhecer a realidade local ocorreram conversas com os moradores e pescadores que frequentam a praia e o bairro Ponta Verde. A terceira e quarta ida a campo foram voltadas para etapas de registro fotográfico e visita dos pontos indicados por moradores locais.

\section{RESULTADOS E DISCUSSÃO}

\subsection{Breve Histórico do Turísmo no Maranhão}

No Brasil, o turismo começou a expandir-se de acordo com Santos e Teixeira $(2009$, p.3) "a partir da década de 1980, com a liberação da economia nacional, provocando uma explosão do setor". Em parâmetros legais, o Artigo 180 da Constituição Federal de 1988 atribui responsabilidades nas diferentes esferas governamentais com a premissa de um turismo que promova o desenvolvimento social e econômico.

Conforme Costa (2016), a partir da década de 1980, os investimentos e os diversificados instrumentos de planejamento começaram a ser executados. Já na década de 1990, foi instituído o Plano Nacional de Municipalização do Turismo (PNMT) que contribuiu para acelerar o processo de descentralização administrativa voltada ao turismo, e promoveu o desenvolvimento do turismo interno, com base nas potencialidades locais. Esse contexto culminou na definição de "um papel estratégico ao setor de turismo nos Planos de Desenvolvimento Local, recebendo especial atenção da OMT, com estudos e sugestões de modelos de planejamento, atentandose para as potencialidades locais (SANTOS; TEIXEIRA, 2009).

No entanto, essa ideia de expansão do turismo litorânea ordenado demorou a ser veiculado no estado, Ferreira (2007, p.06) afirma que "como aconteceu na escala da União, a preocupação com o turismo no Maranhão é remontada a 1962 quando foi criado o Departamento de Turismo e Promoção do Estado" que seguia parâmetros nacionais. O desenvolvimento do turismo se deu a partir do Plano de Desenvolvimento Integral do Turismo (Plano Maior) 2000-2010, o qual direcionou as ações de fomento e de estruturação dos destinos turísticos maranhenses, considerando rotas e estratégias (RODRIGUES et al., 2014).

Ferreira (2007) pontua alguns fatos que antecederam e que foram responsáveis pela elaboração deste plano, como: em 1962 a criação do Departamento de Turismo e Promoção do Estado; em 1968 instituição do Fundo de Investimento do Turismo(FURINTUR); e no ano de 1976 houve a efetivação da Empresa Maranhense de Turismo (MARATUR), que foi transformada posteriormente em Sub-Gerência Estadual de Turismo, no ano 2003, passou a ser denominada de Agência de Desenvolvimento do Turismo (ADETUR). Em 2004, tornou-se a Secretaria de 
Estado Extraordinária para o Desenvolvimento do Turismo (SEEDETUR).

A criação e ampliação dessas instituições foi a base para o Plano de Desenvolvimento Turístico do Maranhão - PDTM, de acordo com Ferreira $(2007$, p.07) em sua primeira edição foi desenvolvido seguindo três etapas a saber: " 1 a - diagnóstico (1999); $2^{\text {a }}$ - definição das estratégias (1999); $3^{\text {a }}$ - estruturação (2000 a 2002) e consolidação (2003 a 2010)". No que consiste a efetivação do Plano, segundo o autor, o Estado possuía um grande potencial turístico inerente a seus atributos naturais. Em consoante com o PDTM, para o desenvolvimento das atividades turísticas foram selecionados apenas 19 municípios, distribuídos em cinco polos: São Luís, Lençóis Maranhenses, Delta das Américas, Floresta dos Guarás e o da Chapada das Mesas.

Contudo, no ano de 2010, de acordo com Costa (2016) no sentido de seguir com o movimento de expansão da atividade turística, a SETUR-MA elaborou um novo plano de turismo, conhecido como Plano Maior 2020, no qual se tinha a pretensão de planejar o desenvolvimento do turismo no estado por uma década.

O referido plano ocorreu em três fases: análise da situação atual do turismo, depois o planejamento estratégico e, por último, o plano operacional. No que tange à regionalização feita a partir do Plano Maior 2020, é possível inferir que o plano contempla 68 municípios de interesse turístico, distribuídos em dez polos, a saber: Polo São Luís, Polo Munim, Polo Parque dos Lençóis Maranhenses, Polo Delta das Américas, Polo Floresta dos Guarás, Polo Amazônia Maranhense, Polo Chapada das Mesas, Polo Cocais, Polo Lagos e Campos Floridos, Polo Serras, Guajajaras, Timbira e Kanela (COSTA, 2016).

\subsection{Aspectos Geofísicos da Área de Estudo}

As zonas costeiras obtiveram ao longo do tempo relevância social no turismo, na economia e no lazer. No Brasil, as áreas costeiras permitiram o início dos processos de colonização, passando a abrigar as principais cidades do país, assim como no Estado do Maranhão através da primeira cidade fundada e também capital, São Luís. O Estado do Maranhão, possui a segunda maior extensão costeira do país, cotadas em aproximadamente $640 \mathrm{~km}$, com presença de exuberantes ecossistemas costeiros.

Decorrente do fato das zonas costeiras possuirem elementos paisagisticos bucólicos que atraem investimentos econômicos, grande parte dessas áreas passam por rigorosos processos de urbanização que associados a falta de planejamento territorial resultam em problemas de ordem social e ambiental, como a sobrecarga dos ecossistemas, especulação imobiliária, urbanização desordenada, privatizações de espaços públicos, dentre outros (COSTA, CUNHA e FARIAS FILHO, 2015).

A Praia de Ponta Verde possui uma série de problemas, como os citados anteriormente, estão atrelados a um processo de urbanização desordenada em curso, o que compromete a estabilidade das características ambientais do local. É possível citar alguns problemas, entre eles destacam-se: os processos de erosão - intensificados a partir das intervenções antrópicas, ocasionados principalmente pelo desmatamento e queima da vegetação que ocorrem próximos das áreas costeiras; a extração de minerais não metálicos - que acontecem na área da praia e em locais próximos; e por fim o lançamento de efluentes domésticos e resíduos sólidos.

O local de estudo está situado no Golfão Maranhense, caracterizado como a grande reentrância, constituída por um complexo sistema estuarino que contém baías, estuários e várias ilhas, dentre elas, a Ilha do Maranhão. Geologicamente a área de estudo conta com a presença de depósitos arenosos datados do Quaternário, conta ainda com a presença de argilas adensadas com areia fina e depósitos marinhos litorâneos, referentes aos depósitos de sedimentos quartzosos, esbranquiçados, classificados como Neossolos Quartzarênicos Órticos Alumínicos (SILVA, 2012). O solo é arenoso possuindo baixa fertilidade natural, elevada acidez e baixa potencialidade agrícola (GOMES et al., 2007), apresentando ainda pouca resistência aos processos erosivos.

Segundo Pinheiro (2002), a parte costeira da Ilha do Maranhão possui topografia suave e somada aos demais fatores como a insolação, a latitude, a maritimidade, e com os sistemas regionais de circulação atmosférica, possui poucas diferenciações térmicas. O clima da ilha como um todo, segundo Koppen (1948), está dentro da classificação de Aw, com duas estações distintas: uma chuvosa de janeiro a junho; e um período seco de julho a dezembro. O índice pluviométrico médio da Ilha do Maranhão fica em torno de $2000 \mathrm{~mm} / \mathrm{ano}$ e as temperaturas ao ano variam entre 25,5 e $28,6^{\circ} \mathrm{C}$ (IMESC, 2011).

Em seu contexto geomorfológico, a Praia de Ponta Verde possui falésias que podem ser de dois tipos: as ativas e as inativas ou paleofalésias. As ativas são formações com alta declividade e que sofrem com a ação marinha, que é responsável pela modelagem destas, possuindo um equilíbrio morfodinâmico instável e suscetível a desmoronamento. As inativas são falésias que não sofrem mais com a ação marinha e estão moderadamente estáveis e cobertas pela vegetação (ROSSETI, 2008).

Com relação as características da flora, se destacam com a forte presença de palmáceas, plantas típicas da restinga e com a presença predominante de vegetação secundária arbustiva, os principais fragmentos de vegetação ainda existentes na ilha estão na zona rural (GOMES, et al., 2015), como o caso do bairro de Ponta Verde.

\subsection{Caracterização dos processos de erosão na Área de Estudo}

Áreas costeiras, costas litorâneas ou litorais, são depósitos sedimentares arenosos, formados principalmente por ações marítimas e eólicas, são nesses espaços que ocorrem os processos de modificação do relevo podendo ser constantemente observados (TEIXEIRA et al., 2009).

Nessas áreas, as feições geomorfológicas são ocasionadas por processos geológicos e pelos agentes intempéricos externos vento e mar, segundo Sousa, et al,.(2005), a ação das ondas sobre costas altas causa erosão, promovendo o recuo da linha de costa, ou seja, estes processos são de ordem natural, mas tendem a tornarem-se severos a partir de intervenções antrópicas.

A praia está em volta de formações tabulares formadas pelos sedimentos da Formação Barreiras, isso associado a sua composição mineralógica - siltitos, argilitos, arenitos e folhelhos - e atrelado ao fato de estar localizada em uma área de grande dinâmica intempérica com a variação das marés e ações dos 
ventos, traz como consequências a suscetibilidade aos processos de erosão.

As formações das falésias se deram pelas características do pacote geológico do processo de abrasão, e vários processos erosivos. Ainda é possível inferir que as falésias possuem trechos com solo exposto, tornando-as suscetíveis ao intemperismo por agentes modeladores como a chuva, o vento e a dinâmica de maré. Ademais apresenta trechos cobertos por vegetação capazes de proteger dos agentes erosivos, o que garante maior estabilidade.

Na Figura 2, é possível visualizar alguns processos de erosão presentes na área de estudo. $\mathrm{Na}$ base das falésias ocorre o fenômeno erosivo a partir dos movimentos de preamar e baixamar, na face é perceptível a presença de sulcos devido a ação da chuva, inerente a seu processo de escoamento superficial. À vista disso, é possível ponderar que os moradores do local realziam obras de contenção nas bases das falésias, não obstante, são constantemente destroçadas pela ação da natureza.

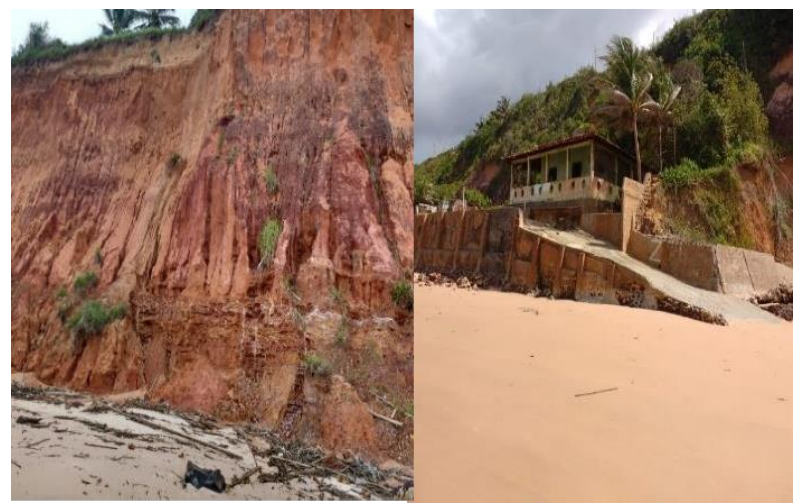

Figura 2 - Processo de erosão na praia de Ponta Verde. Fonte: Acervo de Pesquisa (2019).

\subsection{Processo de Ocupação}

O bairro e a praia de Ponta Verde sofrem com o processo de urbanização, com pouca estrutura turística, possui casas de veraneio, bar e restaurante. Em virtude disso, a pesquisa buscou mostrar alguns dos atrativos turísticos da Praia de Ponta Verde, destacando os aspectos naturais particulares, que compõem um cenário próprio formado de praias, falésias, manguezais e coqueirais. O rico potencial de suas paisagens contribui de forma significativa para o investimento no turismo.

O crescimento populacional desordenado do bairro de Ponta Verde intensifica-se em direção a extremidade do topo das falésias, visto que há indivíduos que residem em casas nestes locais, é notório o eminente risco de deslizamento de terra, devido a retirada da vegetação para a construção civil. Como consequências, essa exposição ao risco somada a fatores que aumentam os processos erosivos, podem levar a perda dessas estruturas, dos bens materiais e até mesmo causar a morte desses moradores.

Devido a essa sobrecarga, verificou-se que a construção de um empreendimento habitacional, como o loteamento Portal Mar Residencial e ocupações irregulares, somadas as limitações de infraestrutura da área contribuem para uma série de problemas socioambientais como: o desmatamento da vegetação, lançamento de resíduos sólidos (afetam diretamente a área de praia), pavimentação deficitária e o fluxo de carros na faixa de areia, conforme Figura 3:

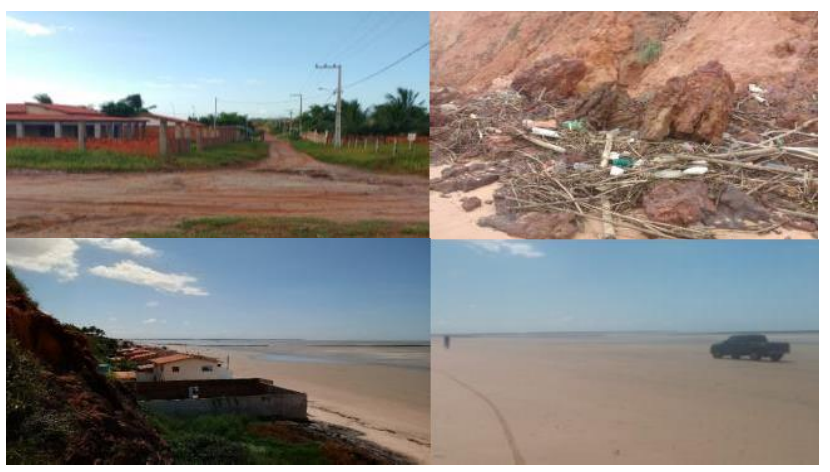

Figura 3 - Problemas socioambientais na praia de Ponta Verde, São José de Ribamar. Fonte: Acervo de pesquisa (2019).

Um dos motivos para ter esse fluxo de carro na faixa de praia é a ausência de fiscalização do poder público e a baixa circulação de banhistas, contudo existe o risco eminente de acidente frente a movimentação de pescadores na área. Ações públicas voltadas

para as práticas turísticas considerando as características

socioambientais poderiam ser um diferencial na área, essas atividades planejadas e integradas podem trazer incentivos em

vários setores sociais. O Ecoturismo pode ser uma opção relevante para o local, tendo em vista, as potencialidades naturais costeiras, além do fato de parte dos moradores do bairro de Ponta Verde subsistirem com atividades de pesca e coleta de mariscos.

Ponta Verde destaca-se ainda, por possuir um sítio

arqueológico situado no entorno da praia e áreas que ainda conservam sistemas de pesca artesanais como camboas, currais e áreas aptas para extração de marisco, que podem ser o diferencial de um passeio náutico, um passeio pela orla ou pesca artesanal, sendo esta realizada pelo turista acompanhado por pescadores locais.

\subsection{Identificação de pontenciais pontos turísticos da praia de Ponta Verde}

Na Figura 4 é apresentado um mapa de localização e distribuição dos principais pontos turísticos da praia de Ponta Verde. Dentre estes pontos, foram identificados 9, como sendo pontos de interesse, sendo eles: (1) entrada de Panaquatira; (2) localização de mirante na praia de Ponta Verde; (3) área de camboa, são covas abertas na beira do mar para que a água nela penetre e forme uma espécie de piscina que possa conter peixes miúdos; (4) localização de afloramento de rochas; (5) áreas de banho; (6) ponto final da praia de Ponta Verde; (7) início da praia de Itapari; (8) sítio arqueológico; (9) entrada e saída de Ponta Verde. A seguir, estão descritos os principais potenciais da praia de forma detalhada. 


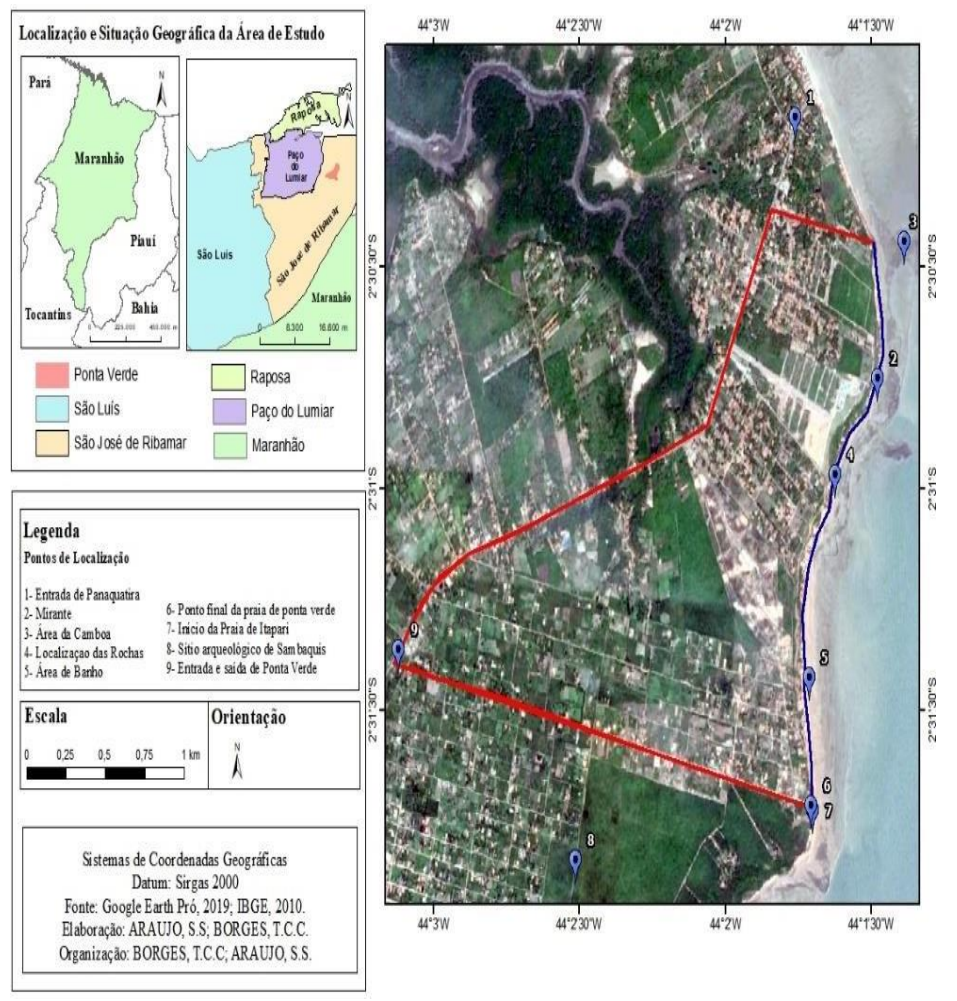

Figura 4 - Localização e distribuição dos pontos de parada. Fonte: Elaboração própria (2019).

\subsubsection{Praia}

O local de estudo se destaca por ter uma extensa faixa praial, cotado em aproximadamente $2,5 \mathrm{~km}$ de extensão, localizada entre duas outras praias: Panaquatira, que já possui características bem urbanizadas, e a praia de Itapari que apresenta poucos sinais de urbanização. Desta forma, a proposta de se fazer um passeio entre as praias é significativo e diversificado. Ressalta-se que, a Praia de Ponta Verde, tem a presença de afloramentos rochosos, sendo um local ideal para banho de mar, passeios e caminhadas, pois diferentemente de outras praias, o fluxo de pessoas não é intenso.

\subsubsection{Falésias e Local de Mirantes}

As falésias presentes na orla da praia de Ponta Verde apresentam as seguintes características: feições íngremes, com alturas variando entre 6 a 30 metros, presentes na praia do início ao fim. O local tem potencial para registros fotográficos, sendo utilizado pelos moradores como via de acesso de um ponto outro da praia, bem como, para a fixação de estruturas chamadas de Mirantes, que se configuram como estruturas fixadas nas falésias, geralmente construídas de madeira com vários metros de altura.
Os mirantes proporcionam uma visão parorâmica e contemplativa da paisagem da Praia de Ponta da Verde e do horizonte marinho.

Sendo assim, outro ponto que pode ser explorado são as partes fixas das falésias (Figura 5), onde podem ser construídos mirantes. Na praia já existem mirantes, mas são feitos com material inapropriados e em áreas inadequadas, dessa forma, é necessário um estudo de solo aplicado as falésias, para determinar as áreas que apresentam estruturas fixas de solo que consigam manter essas estruturas.

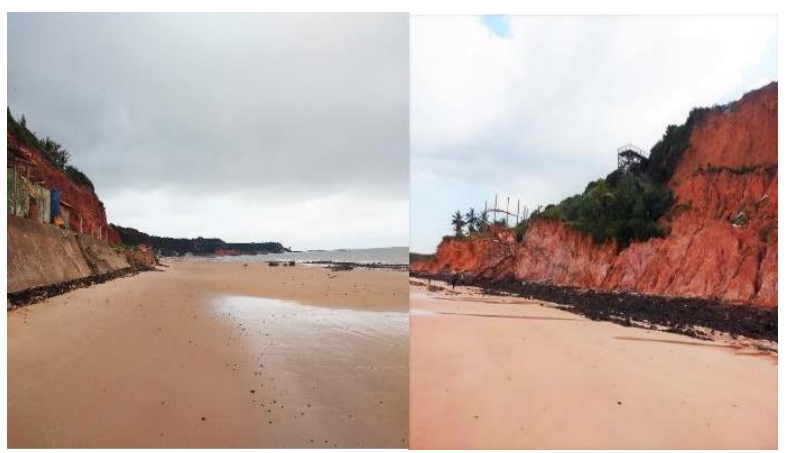

Figura 5 - Falésias e Mirantes. Fonte: Acervo de pesquisa (2019). 


\subsubsection{Afloramentos rochosos na praia e camboas}

Os afloramentos rochosos, conforme a Figura (6), podem ser vistos em partes da Praia de Ponta Verde e possuem tamanhos variados e podem chegar a $2 \mathrm{~m}$ de altura, sendo um dos potenciais turísticos da praia. Nesses locais há presença de crustáceos e moluscos e suas carapaças, popularmente conhecida como conchas, que ficam espalhadas na beira do mar e entre as rochas.

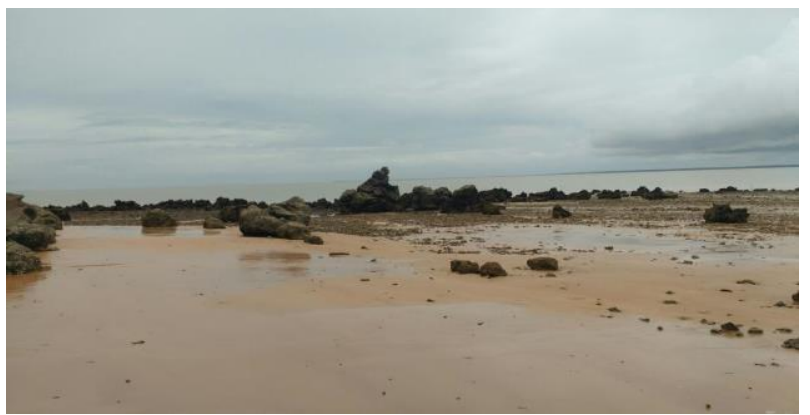

Figura 6 - Afloramentos rochosos Fonte: Acervo de pesquisa (2019).

A Praia de Ponta Verde apresenta sistemas de pesca artesanais, estas podem ser inclusas em possíveis paradas de passeios. Entre as quais, pode-se citar "as camboas" (Figura 7), são construções feitas por índios, destinados a pesca e que atualmente são utilizadas por moradores locais. Uma sugestão para um roteiro turístico seria a visita desse local em que o visitante pudesse participar da pesca artesanal sendo auxiliados pelos pescadores locais. Após a pesca o turista poderá seguir a um restaurante local e consumirá o que ele pescou, assim desfrutará de uma experiência cultural.

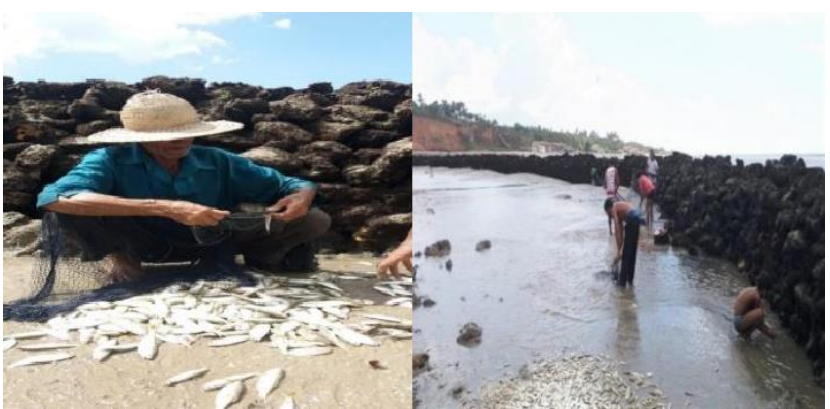

Figura 7 - Pontos aptos à implantação de roteiros turísticos. Fonte: Acervo de pesquisa (2019).

\subsubsection{Sítio Arqueológico}

O sítio arqueológio mapeado neste trabalho não encontra-se inserido na área de Ponta Verde, contudo está localizado em uma região próxima no "povoado de Itapari, o local apresenta fósseis de sambaquis, o sítio está implantado sobre uma falésia, característica da baía de São José" (BANDEIRA, A., 2018, p. 328). Devido ao fato do local estar próximo da Praia de Ponta Verde, é ideal à inserção em uma possível rota turística, pois ao conhecerem os fósseis de sambaquí, os turistas podem ser destinados para a Praia de Ponta Verde, onde serão realizadas atividades de lazer, tais como: banho, piquenique, além de momentos para tirar belas fotografias.

A Figura 8 mostra os locais potenciais que podem ser visitados e possíveis pontos de atividades turísticas, bem como, áreas de reconhecimento do local apresentadas anteriormente. No intuito de espacializar os principais locais de interesse da praia, foi elaborado o mapa que poderá ser usado para criação de um roteiro turístico, desde a entrada da praia até o seu limite final 


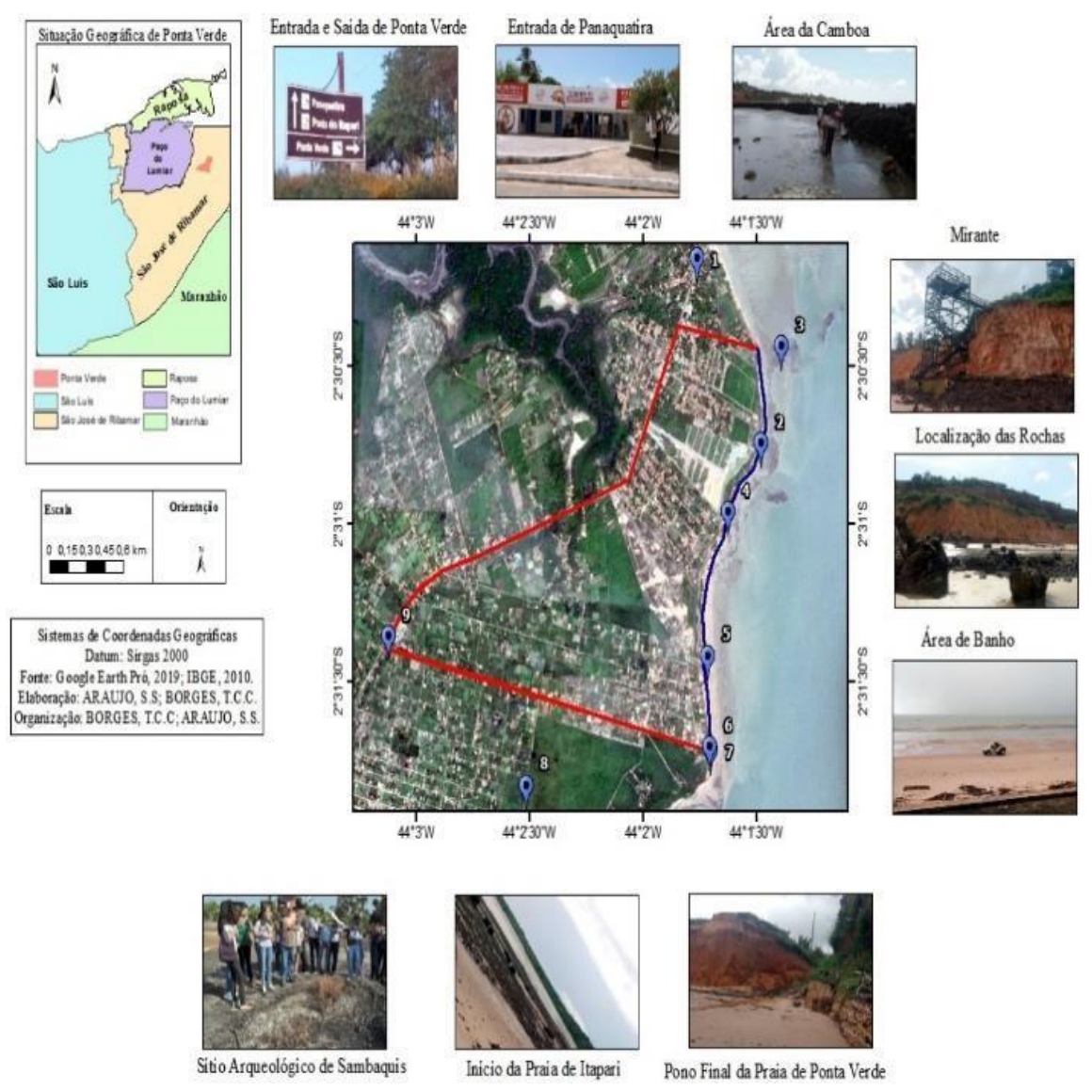

Figura 8 - Atrativos dos Pontos de Parada. Fonte: Elaboração própria (2019).

Entre as diferentes formas de turismo ficou evidente que a Praia de Ponta Verde possui potenciais naturais característicos de uma área a ser explorada pelo Ecoturimo. De acordo com Brasil (2010), essa atividade preza pela conservação ambiental aliada ao desenvolvimento das comunidades locais, que deve ser formado sob o princípio da sustentabilidade, com base em referenciais teóricos e práticos que garantam a legalidade da atividade. Dessa maneira, a presença de problemas socioambientais encontra resposta no ecoturismo, uma proposta que visa conscientizar e manter o equilíbrio ambiental do local.

Ainda que cause impactos, espera-se minimizar o possível grau de prejuízo que este ambiente possa sofrer decorrente do ecoturismo. Sendo assim, serão amenizados os transtornos, como o processo de erosão relacionado a ações antrópicas e os resíduos sólidos. Em relação ao descarte de resíduos sólidos na área da Praia de Ponta Verde, pode ser realizada a coleta de resíduos por agentes de limpeza pública, tanto para resíduos trazidos pelo mar quanto para aqueles descartados por indivíduos diretamente na praia. Além disso, o poder público pode distribuir recipientes adequados de descarte (lixeiras) e realizar campanhas de conscientização e sensibilização de práticas corretas de descarte.

\section{CONSIDERAÇÕES FINAIS}

O desenvolvimento do turismo em Ponta Verde pode ocorrer em parceria com municípios vizinhos - São Luís, Raposa e Paço do Lumiar. Tais parcerias poderiam trazer benefícios para a região, com a geração de trabalho e renda nos municípios envolvidos, o que influenciará na resolução de problemas de ordem social, como segurança pública e apropriação indevida de lotes de terras. Por fim, pode-se afirmar que as potencialidades naturais, somadas aos fatores de ordem econômica, sociais e culturais, são vistos de forma oportuna para o desenvolvimento do turismo.

Em virtude da atividade usar de forma ecologicamente sustentável o patrimônio natural e cultural, com base na conservação, e pela formação de uma consciência ambiental e promoção do bem-estar das populações, a proposta de turismo ideal a ser inserido na Praia de Ponta Verde é o Eoturismo. Em relação aos problemas socioambientais da praia, tendo como principais, os processos de erosão e descarte irregular de resíduos sólidos, busca-se uma proposta turística que consiga manter a harmonia ambiental da área. Além disso, a proposta pode trazer renda para os moradores locais. No curso da consolidação da proposta turística estes estariam engajados em trabalhar no roteiro 
turístico, bem como, em concientizar os turistas e elaborar propostas de limpeza e recolhimento de resíduos sólidos na orla da Praia de Ponta Verde juntamente com o poder público, sendo este de caráter Municipal e/ou Estadual.

\section{REFERÊNCIAS}

BANDEIRA, A. M. Os Sambaquis na Ilha de São Luís, MA: processo de formação, cultura material cerâmica e cronológica. Revista Memorae, v. 5, p. 315-360, 2018.

BANDEIRA, I. C. N.; DANTAS, M. E. Atrativos Geoturísticos, Polos Turísticos e Unidades de Conservação. In: BANDEIRA, I. C. N. Geodiversidade do Estado do Maranhão. Teresina: CPRM, 2013.

BANDEIRA, I. C. N.; Geodiversidade do estado do Maranhão. Teresina: CPRM, 2013. 294 p.

BRASIL. Ministério do Turismo. Ecoturismo: orientações básicas. 2. ed. Brasília: Ministério do Turismo, 2010. 90 p.

COSTA, C. R. R. O Maranhão e a fronteira de expansão do turismo litorâneo na periferia do Brasil. In: XVIII Encontro Nacional de Geógrafos - ENG, 2016, São Luís - MA. Anais Eletrônicos do XVIII ENG. São Luís: AGB São Luís, 2016. v. 1.p. 01-12.

COSTA, M; CUNHA, E. C; FARIAS FILHO, M. S. A influência dos grandes empreendimentos industriais no processo de urbanização e no incremento da problemática ambiental na Ilha do Maranhão. In: FARIAS FILHO, M. S; CELERI, M. J. (org.). Geografia da Ilha do Maranhão - São Luís, MA: EDUFMA, 2015.

CUNHA, L. A Definição e o Âmbito do Turismo: um aprofundamento necessário. ReCiL - Repositório Científico Lusófona, 2010. Disponível em: <http://recil.grupolusofona.pt/bitstream/handle/10437/665/ A\%20Defini\%C3\%83\%C2\%A7\%C3\%83\%C2\%A3o\%20e $\% 20 \mathrm{o} \% 20 \% \mathrm{C} 3 \% 83 \% \mathrm{E} 2 \% 80 \% 9$ Ambito\%20do\%20Turism o.pdf? sequence=1>. Acesso em 19 jul. 2019.

FERREIRA, A. J. A. O turismo e a produção do espaço no estado do Maranhão, Brasil. Revista Electrónica de Geografía y Ciencias Sociales, Barcelona, v. XI, n. 245 (58), ago. 2007. (Nueva serie de Geo Crítica. Cuadernos Críticos de Geografía Humana). Número extraordinário dedicado al IX Colóquio Internacional de Geocrítica.

FREITAS, R. F. O método científico: algumas considerações acerca do uso das várias espécies de procedimentos em ciência conforme manuais da disciplina metodologia do trabalho científico. Revista Interfaces: saúde, humanas $e$ tecnologia. V. 4, n 13, p. 110-116, 01 de dezembro, 2017. Disponível em: https://interfaces.leaosampaio.edu.br/index.php/revistainterfaces/article/view/572> Acesso em Dez. 2019.
GOMES, A. R. et al. Caracterização da mineração de minerais não metálicos na Ilha do Maranhão-MA. In: FARIAS FILHO, M. S.; CELERI, M. J. Geografia da Ilha do Maranhão. São Luís: EDUFMA, 2015.

IGNARRA, L. R. Fundamentos do Turismo. 2. ed. São Paulo: Pioneira Thompson Learning, 2003.

INSTITUTO MARANHENSE DE ESTUDOS SOCIOECONÔMICOS E CARTOGRÁFICOS (IMESC). Situação Ambiental da Ilha de São Luís. São Luís: IMESC, 2011.57 p.

KÖPPEN, W.; Climatología: Com un estudio de los climas de la tierra. Mexico: Fondo de Cultura Econômica, 1948. 479 p.

MALDONADO, C. O turismo rural comunitário na América Latina: gênesis, características e políticas. In: Turismo de Base Comunitária. Diversidade de olhares e experiências brasileiras. BARTHOLO, R.; SANSOLO, D. G.; BURSZTYN, I. Letras e Imagens, 2010.

ORGANIZACIÓN MUNDIAL DEL TURISMO (OMTUNWTO). Panorama OMT del turismo internacional, Edición 2019.

PINHEIRO, J. M. Análise do Sistema Costeiro da Ilha do Maranhão. 2002. Disponível em: $\langle$ http://lsie.unb.br/ugb/sinageo/4/1/57.pdf $>$. Acesso Maio 2018.

RODRIGUES, L. M.; LIMA, T. J. C.; SILVA, D. L. B.; CORTINA, A. Sentidos do Lugar: Olhares do setor turístico oficial do Governo do Estado do Maranhão, Brasil. Revista Turismo \& Desenvolvimento., v. 2, p. 283, 2014.

ROSSETTI, D. F. Ambientes costeiros. In: FLORENZANO, T. G. (Org.). Geomorfologia, conceitos e tecnologias atuais. 1ed.São Paulo: Oficina dos Textos, 2008, v. 1, p. -320.

SANTOS, S. R.; TEIXEIRA, M. G. C. Análise do Plano de Desenvolvimento Turístico do Estado do Maranhão: potencialidades e entraves na gestão de pólo turístico. Turismo. Visão e Ação (Itajaí), v. 11, p. 201-217, 2009. Disponível em: < www.univali.br/revistaturismo $>$. Acesso em: 10 julh. 2018.

SILVA, Q. D. Mapeamento Geomorfológico da ilha do Maranhão. 2012. 249 f. Tese (Doutorado)- Universidade Estadual Paulista, faculdade de ciências e tecnologia, Presidente Prudente, 2012.

SOUSA, I. G.; Habitação social no programa minha casa minha vida: avaliação do Residencial Pitangueiras, São José de Ribamar/Ma, sob as preferências do usuário. Dissertação (Mestrado) - Programa de Pós-Graduação da Faculdade de Arquitetura e Urbanismo da Universidade de Brasília, 2017

SOUZA, C. R. G.; SUGUIO, K.; OLIVEIRA, A. M. S.; OLIVEIRA, P. E.; Quaternário do Brasil. Ribeirão preto: Holos, 2005. 382 p. 
TEIXEIRA, W. et al. Decifrando a Terra. 2. ed. São Paulo: Companhia Editora Nacional, 2009.
VIEIRA, A. R. M. Planejamento e políticas públicas de Turismo: análise dos módulos operacionais do programa de regionalização do turismo no polo São Luís- MA. Dissertação (Mestrado)- Universidade de Brasília, Centro de excelência em Turismo, Mestrado profissional em Turismo, 2011.

Recebido em: 10/10/2019

Aceito para publicação em: 23/05/2021 